\title{
Excessive daytime sleepiness, metabolic syndrome, and obstructive sleep apnea: two independent large cross-sectional studies and one interventional study
}

Xinyi Li $i^{1,2,3 \dagger}$, Hengye Huang ${ }^{4 \dagger}$, Huajun $X^{1,2,3^{*}}$, Yue Shi ${ }^{4}$, Yingjun Qian ${ }^{1,2,3}$, Jianyin Zou ${ }^{1,2,3}$, Hongliang Yi $i^{1,2,3^{*}}$, Jian Guan ${ }^{1,2,3}$ and Shankai Yin ${ }^{1,2,3}$

\begin{abstract}
Background: Obstructive sleep apnea (OSA) and excessive daytime sleepiness (EDS) were considered to contribute to MetS. This study was performed to assess the association between MetS and EDS in two independent large-scale populations, and in subjects who underwent upper-airway surgery.

Methods: A total of 6312 patients without self-reported depression and 3578 suspected OSA patients were consecutively recruited, during health screening examinations and from our sleep center, respectively. A total of 57 subjects with OSA who underwent upper-airway surgery were also included. Demographic, anthropometric, biochemical, and polysomnographic data were obtained.

Results: In the health screening examination group, 233 (9.23\%) women and 350 (10.93\%) men had complaints of EDS. A total of $229(7.04 \%)$ women and 1182 (36.88\%) men met the criteria for MetS. In the OSA group, 147 (21.18\%) women and 1058 (36.69\%) men reported EDS. In addition, 93 (13.4\%) women and 1368 (47.43\%) men reported MetS. In the health screening examination group, EDS did not contribute significantly to MetS $(\mathrm{OR}=1.125,95 \% \mathrm{Cl}: 0.907-1.395 ; p=0.283)$. In the OSA group, EDS significantly contributed to MetS ( $\mathrm{OR}=1.249,95 \% \mathrm{Cl}: 1.063-1.468 ; p=0.007)$; however, the results were not significant after adjusting for sleep variables ( $\mathrm{OR}=1.071,95 \% \mathrm{Cl}$ : 0.905-1.268; $p=0.423$ ). Upper-airway surgery did not affect cardio-metabolic variables in OSA patients with or without EDS.
\end{abstract}

Conclusions: EDS was not associated with MetS in two independent large-scale cohorts. In addition, upper-airway surgery did not affect components of MetS in OSA patients with and without EDS.

Keywords: Obstructive sleep apnea, Excessive daytime sleepiness, Metabolic syndrome, Upper-airway surgery

\section{Backgrounds}

Obstructive sleep apnea (OSA) is one of the most common sleep-disordered breathing (SDB) patterns, and is characterized by apnea, hypopnea, oxygen desaturation, and micro-arousals due to recurrent episodes of partial or complete upper airway collapse during sleep [1]. The ensuing cardinal symptoms of OSA, such as excessive daytime sleepiness (EDS) can persist throughout the day,

\footnotetext{
*Correspondence: sunnydayxu2010@163.com; yihongl@126.com

${ }^{+}$Xinyi Li and Hengye Huang contributed equally to this work.

${ }^{1}$ Department of Otolaryngology Head and Neck Surgery \& Center of Sleep

Medicine, Shanghai Jiao Tong University Affiliated Sixth People's Hospital,

Yishan Road 600, Shanghai 200233, China

Full list of author information is available at the end of the article
}

leading to depression [2], low productivity and poor work performance [3], increased risk of traffic accidents and related deaths [4], and impaired quality of life [5].

EDS is also a common problem, with a prevalence of 9.4\% in the Chinese population according to an Asian multi-ethnic study [6]. The prevalence of EDS in patients with OSA is even higher, at $16-22 \%$ [7]. The high prevalence of EDS imposes a social and economic burden worldwide. Recently, several clinical studies have shown that EDS is associated with individual components of metabolic syndrome (MetS) such as obesity [8], insulin resistance, $[9,10]$ and hypertension [11]. However, few studies have explored the relationship between

(c) The Author(s). 2019 Open Access This article is distributed under the terms of the Creative Commons Attribution 4.0 International License (http://creativecommons.org/licenses/by/4.0/), which permits unrestricted use, distribution, and 
EDS and MetS as a complete entity, rather than in terms of its individual components. One community study [12] and two clinical studies $[13,14]$ assessed the relationship between EDS and MetS; however, the findings should be interpreted with caution because the definition of MetS in the community study focusing on the general population was inaccurate, where fasting serum glucose, triglycerides (TG), and high-density lipoprotein-cholesterol (HDL-c) were not measured [12]. The two crosssectional studies focused on males and patients with severe OSA, respectively, and the results may therefore have been biased [13, 14]. The relationship between MetS and EDS in patients with or without OSA is complex and poorly understood.

Continuous positive airway pressure (CPAP) is the first-line treatment for OSA and can decrease levels of cholesterol, insulin, and the insulin resistance index in subjects with EDS, although it does not affect these variables in subjects without EDS [15]. Upper-airway surgery is another common therapeutic method for OSA that can improve daytime sleepiness in nonobese patients with OSA, especially in patients with severe OSA [16]. In a retrospective case review, upper-airway surgery improved blood lipid levels in patients with OSA [17]. However, whether abolishment of nocturnal apneas by upper-airway surgery improves metabolic status in patients with or without EDS remains unclear.

In this study, we explored whether EDS is independently associated with MetS in three independent groups: 1) a general population (subjects undergoing health screening examinations), 2) a suspected OSA population, and 3) OSA patients that underwent upper-airway surgery.

\section{Methods \\ Participants \\ Cohort 1}

Between March 2011 and September 2011, a total of 9310 subjects without self-reported depression were consecutively recruited during health screening examinations without PSG diagnosis conducted at the Shanghai JiaoTong University Affiliated Sixth People's Hospital. The final sample comprised 6312 participants. The exclusion criteria presented in Supplementary Material and Data 1.1.

\section{Cohort 2}

A total of 4730 patients suspected to have OSA were consecutively enrolled from July 2007 to July 2015 with overnight PSG (Alice 4 or 5; Philips Respironics, Pittsburgh, PA, USA) at our sleep center. A total of 3578 subjects were included in the final analysis. The exclusion criteria presented in Supplementary Material and Data 1.2.

\section{Cohort 3}

Between January 2013 and January 2014, patients with OSA who had undergone upper-airway surgery [uvulopalatopharyngoplasty], recruited from our sleep center, were included. All participants underwent polysomnography (PSG) monitoring before upper-airway surgery and after the 6-month follow-up. Exclusion criteria included: 1) severe comorbidities, 2) receiving other treatments for OSA after upper-airway surgery, and 3) taking anti-metabolic medications. Finally, 57 subjects were included in the statistical analysis.

Written informed consent was obtained from all subjects. Our studies were performed according to the Declaration of Helsinki and were approved by the Ethics Committee of Shanghai Jiao Tong University Affiliated Sixth People's Hospital.

\section{Daytime sleepiness assessment}

Daytime sleepiness was evaluated using the validated ESS questionnaire, as described previously [18]. The ESS includes eight questions quantifying the individual's sleep propensity and likelihood of "dozing" ( $0=$ never, 1 = slight, 2 = moderate, and 3 = high probability) in different situations. The sum of the ESS score ranges from 0 to 24 , with higher scores representing a higher degree of sleepiness. A cutoff EDS score of $>10$ was defined as EDS [19].

\section{Metabolic syndrome}

Anthropometric measurements seen Supplementary materials and methods 1.3. Fasting blood samples were drawn from every participant in the morning. Weight, height, neck circumference (NC), waist circumference (WC), and hip circumference $(\mathrm{HC})$ were measured following standardized procedures. Waist-hip ratio (WHR; WC/ $\mathrm{HC}$ ), and body mass index (BMI; weight/height2) were calculated. Serum fasting glucose and serum fasting lipid profiles [i.e., total cholesterol (TC), TG, high density lipoprotein (HDL), and low density lipoprotein (LDL)] were measured using an $\mathrm{H}$ 7600 autoanalyzer (Hitachi, Tokyo, Japan) in the hospital laboratory, as described previously [20]. Blood pressure were measured in triplicate after at least a 5-min rest using an automated electronic device (Omron Model HEM-752 Fuzzy, Omron Company), and the average value of the three measurements was used for analysis. Adult Treatment Panel-III (ATP-III) criteria with the WC criteria for Asians was used to define MetS [21]. MetS was diagnosed in patients exhibiting at least three of the following metabolic features 1) $W C \geq 90 \mathrm{~cm}$ (in men) and $\geq 80 \mathrm{~cm}$ (in women); 2) $\mathrm{TG} \geq 1.70 \mathrm{mmol} / \mathrm{L} ; 3) \mathrm{HDL}<1.03 \mathrm{mmol} / \mathrm{L}$ (in men) and $<1.30 \mathrm{mmol} / \mathrm{L}$ (in women); 4) systolic blood pressure $(\mathrm{SBP}) \geq 130 \mathrm{mmHg}$ or diastolic blood pressure $(\mathrm{DBP}) \geq 85$ $\mathrm{mmHg}$, or use of antihypertensive drugs; and 5) fasting glucose: $\geq 5.6 \mathrm{mmol} / \mathrm{L}$ or use of antidiabetic drugs. The 
metabolic score was given by the total number of diagnostic criteria for MetS fulfilled. Homeostasis model assessmentestimated insulin resistance (HOMA-IR) was given by (Glucose*Insulin) / 22.5. Insulin resistance was defined as a HOMA-IR index $>2.5$ [22].

\section{Polysomnographic evaluation}

In Cohorts 2 and 3, overnight PSG (Alice 4 or 5; Philips Respironics, Pittsburgh, PA, USA) was performed to assess objective sleep status according to the American Academy of Sleep Medicine (AASM) 2007 criteria [23]. For patients with OSA who underwent upper-airway surgery, preoperative PSG was performed within the 2 weeks prior to upper-airway surgery and postoperative PSG was performed at least 6 months after upper-airway surgery. The full-night PSG sessions included electroencephalogram (EEG), bilateral electrooculogram (EOG), electrocardiogram (ECG), genioglossus electromyogram, thoracic-abdominal movement, nose and mouth airflow, finger pulse oxygen saturation, bilateral leg movement, and body position measurements. Objective sleep parameters such as apnea hypopnea index (AHI), oxygen desaturation index (ODI), mean oxygen saturation $\left(\mathrm{MSaO}_{2}\right)$, lowest pulse oxygen saturation $\left(\mathrm{LSpO}_{2}\right)$, and micro-arousal index (MAI) were calculated using software and manually checked by a skilled technician.

Apnea was defined as a complete cessation of airflow for $\geq 10$ s; hypopnea was defined as a $\geq 50 \%$ reduction in airflow for $\geq 10 \mathrm{~s}$, with $\geq 3 \%$ oxygen desaturation or arousal. Arousal was taken as abrupt shifts in electroencephalographic frequency lasting at least $3 \mathrm{~s}$. AHI was calculated as the mean number of apnea events and hypopnea episodes per hour during sleep. The ODI was calculated as the mean number of oxyhemoglobin desaturation $\geq 3 \%$ events per hour of sleep. The MAI was calculated as the mean number of arousal episodes per hour of sleep. The severity of OSA was categorized as normal $(<5$ events per hour), mild (5-14.9 events per hour), moderate (15-29.9 events per hour), or severe $(\geq$ 30 events per hour) according to the AHI.

\section{Statistical analysis}

All statistical analyses were performed using SPSS (ver. 22.0; SPSS Inc., Chicago, IL, USA) and Analysis of Moment Structures (AMOS) software (ver. 21.0; IBM Corp., Armonk, NY, USA). All raw data were examined for normality before any statistical analysis was performed. If the distribution of any variable was skewed, it was natural logarithm-transformed. To explore the magnitude of each component and subcomponents of MetS in nonEDS and EDS patients in the OSA group, confirmatory factor analysis (CFA) was performed. The models were estimated using the maximum likelihood method. First, congruency between the hypothesized models and empirical data from the EDS and non-EDS subgroups was examined using the chi-square difference test. The fit of the models was then assessed by two incremental model fit indices [comparative fit index (CFI) and root mean-square error of approximation (RMSEA)], as the chi-square test is sensitive to sample size. If the $p$-value for chi-square $>0.05$, the CFI value was $>0.9$ and the RMSEA value was $<0.05$ (good) or $<0.08$ (rational), the CFA model was considered to have a good fit. The effects of upper-airway surgery on components of MetS were analyzed using paired $\mathrm{t}$ tests. A $p$ value $<0.05$ was considered to indicate statistical significance.

\section{Results}

\section{Binary logistic regression analysis}

Basic characteristics of the three cohorts with EDS and MetS were presented in Supplementary Material and Data 2.1(Additional file 1: Tables S1-S7). To assess independent factors associated with MetS in the subjects who underwent health screening examinations, the following variables were entered into the logistic regression models: EDS, age, sex, BMI, smoke and drink. MetS in subjects undergoing health screening examinations was significantly associated with the following variables: age $(\mathrm{OR}=1.019,95 \%$ CI: $1.014-1.024 ; p<0.001)$, sex $(\mathrm{OR}=$ $0.189,95 \%$ CI: $0.158-0.226 ; p<0.001)$, BMI (OR $=1.235$, 95\% CI: $1.207-1.263 ; p<0.001)$, smoke (OR $=1.432$, 95\% CI: $1.218-1.683 ; p<0.001)$. There was no significant association with EDS $(\mathrm{OR}=1.092$, 95\% CI: $0.878-1.357$; $p=0.429$ and alcohol $(\mathrm{OR}=1.089,95 \% \mathrm{CI}: 0.928-1.279$; $p=0.297$ ). To increase our understanding of sex-related differences, the analysis was conducted separately in males and females. No significant association between MetS and EDS was found (OR $=1.169,95 \%$ CI: 0.920 $1.484 ; p=0.201$ in males and $\mathrm{OR}=0.713,95 \% \mathrm{CI}$ : $0.397-1.281 ; p=0.258$ in females) after full adjustment.

To assess independent factors associated with MetS in patients with suspected OSA, EDS, age, sex, BMI, smoke and drink were entered into logistic regression models. The basic characteristics subjects with suspected OSA are listed in Additional file 1: Table S1. Most of subjects were OSA patients, subjects with OSA were more obese and had higher levels of glucose, lipid profiles than those without OSA (Additional file 1: Table S1). MetS in OSA was significantly associated with the following variables: $\operatorname{sex}(\mathrm{OR}=0.214,95 \% \mathrm{CI}$ : $0.163-0.282$; $p<0.001)$, BMI (OR $=1.320$, 95\% CI: $1.287-$ $1.355 ; p<0.001)$, age $(\mathrm{OR}=1.015,95 \%$ CI: $1.008-1.023$; $\mathrm{p}<$ $0.001)$, EDS (OR $=1.241,95 \%$ CI: $1.055-1.460 ; p=0.009)$ and smoke $(\mathrm{OR}=1.350,95 \% \mathrm{CI}: 1.146-1.592 ; p<0.001$. However, when we included sleep variables (AHI, ODI, and MAI) in the model, the association with EDS disappeared $(\mathrm{OR}=1.068,95 \%$ CI: 0.902-1.264; $p=0.447)$. To explore sex differences, we also performed logistic analysis separately in males and females adjusted for age, BMI, smoke and drink. 
In males, no significant relationship between MetS and EDS was found (OR $=1.110$, 95\% CI: 0.930-1.326; $p=0.247)$ after full adjustment, similar to females $(\mathrm{OR}=0.665,95 \% \mathrm{CI}$ : $0.361-1.225 ; p=0.189$ ).

\section{Confirmatory factor analysis (CFA)}

Model estimation and evaluation of the whole OSA group (model 1, Fig. 1)

Measurement models of CFA are listed in Figs. 1, 2 and 3. In these figures, insulin resistance, obesity, lipids and blood pressure are latent independent variables, and glucose, insulin, BMI, WHR, TG, HDL, SBP, DBP were observed indicators. Straight arrows represented causation relationship and double-headed curved arrows are correlations between indicators.

In Fig. 1, the goodness of fit results of a hierarchical fourfactor model for MetS conducted in the whole OSA group are presented $(\mathrm{CMIN}=299.032, \mathrm{df}=21, \quad n=3578, \quad p<$ $0.001, \mathrm{NC}=14.240, \mathrm{CFI}=0.972$, $\mathrm{RMSEA}=0.061$ ). Insulin resistance and obesity were strongly correlated (loading = $0.81, p<0.001)$. The other latent independent variables were not correlated $(P>0.05)$. Insulin resistance was mainly represented by insulin (loading $=0.70, p<0.001$ ). Obesity was mainly represented by BMI (loading $=0.84, p<0.001$ ). Lipid profile was mainly represented by TG (loading $=0.67$, $p<0.001$ ). Finally, blood pressure was represented equally by SBP (loading $=0.81, p<0.001$ ) and DBP (loading $=0.85$, $p<0.001)$.
Model for OSA in the EDS group (model 2, Fig. 2) and nonEDS group (model 3, Fig. 3)

Hierarchical four-order factor MetS models of CFA were created for OSA with and without EDS in Fig. 2 and Fig. 3 $[(\mathrm{CMIN}=133.67, \mathrm{df}=23, n=1205, p<0.001, \mathrm{NC}=5.812$, $\mathrm{CFI}=0.966, \quad \mathrm{RMSEA}=0.063) ; \quad \mathrm{CMIN}=221.854, \mathrm{df}=23$, $n=2373, p<0.001, \quad \mathrm{NC}=9.646, \mathrm{CFI}=0.969, \quad \mathrm{RMSEA}=$ 0.060 , respectively]. In both the OSA with and without EDS groups, MetS was mainly represented by insulin resistance [model 2: loading $=0.93, p<0.001$; model 3 : loading $=0.88$, $p<0.001$ ] and obesity [model 2 : loading $=0.91, p<0.001$; model 3: loading $=0.89, p<0.001]$. Lipids and blood pressure were poorly represented in the MetS models. Furthermore, insulin resistance was mainly defined by insulin [model 2: loading $=0.66, p<0.001 ;$ model 3 : loading $=0.72$, $p<0.001$ ], and obesity by BMI [model 2 : loading $=0.85, p<$ 0.001; model 3: loading $=0.83, p<0.001]$.

To assess the independent relationships of HOMA-IR and obesity with EDS in the OSA group, the following variables were adjusted for: age, sex, and sleep variables (AHI, ODI, and MAI). EDS significantly predicted obesity $(\mathrm{OR}=1.230,95 \% \mathrm{CI}: 1.034-1.463 ; p=0.020)$, but not HOMA-IR (OR = 1.026, 95\% CI: 0.875-1.204; $p=0.750)$.

\section{Effects of upper-airway surgery on components of MetS in patients with OSA, with and without EDS}

Table 1 presents the effects of upper-airway surgery on components of MetS. In OSA subjects with EDS, there

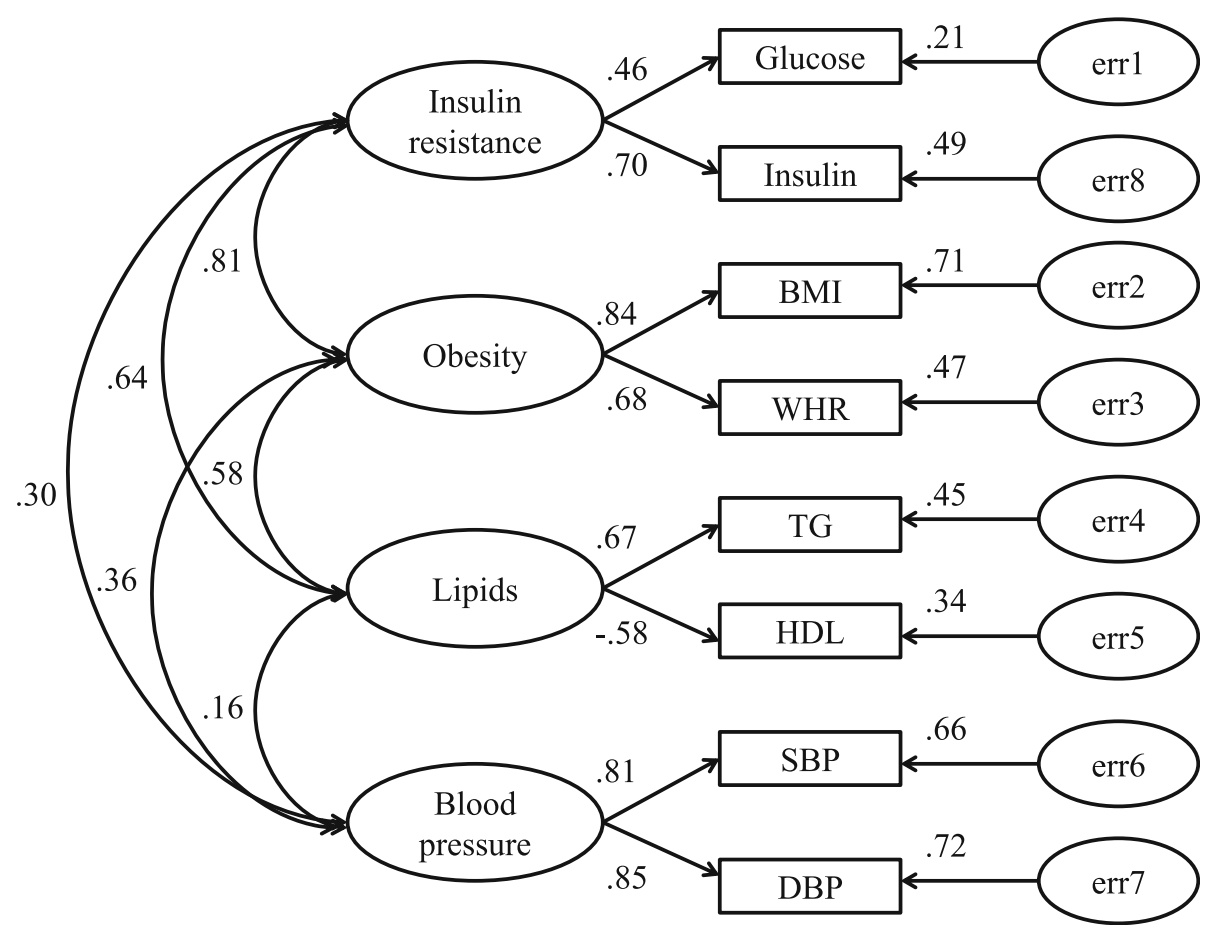

Fig. 1 Model estimation of metabolic risk factors associated with OSA (model 1). Hierarchical 4-factor model of MetS for OSA. CMIN = 299.032, $\mathrm{df}=21, n=3578, p<0.001, \mathrm{NC}=14.240, \mathrm{CFI}=0.972$, RMSEA $=0.061$. 'e' represents residual covariance 


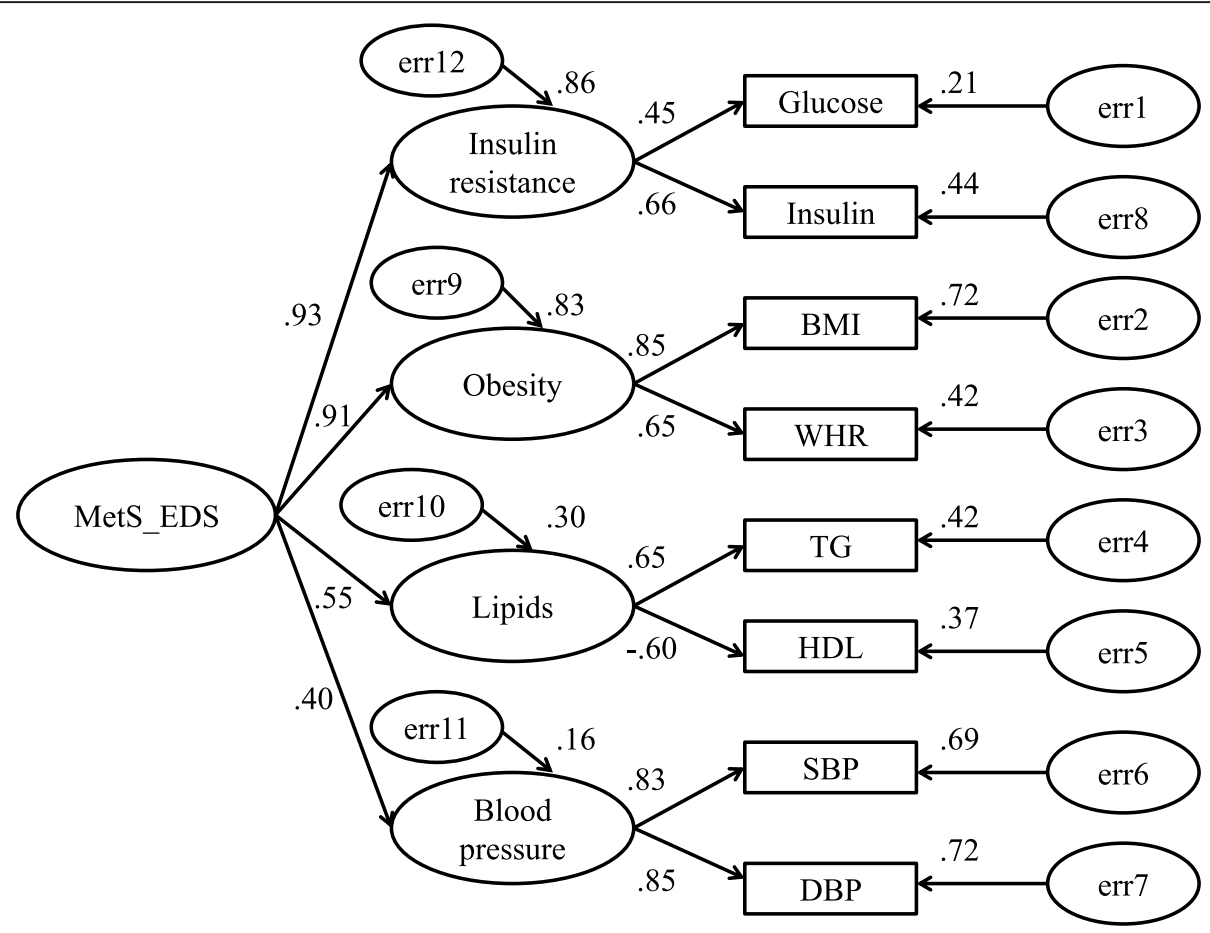

Fig. 2 Model estimation of metabolic risk factors associated with EDS (model 2). Correlated 4-factor model for the EDS. CMIN =133.67, df =23, $n=1205, p<0.001, \mathrm{NC}=5.812, \mathrm{CFI}=0.966$, RMSEA $=0.063)$. ' $\mathrm{e}$ ' represents residual covariance

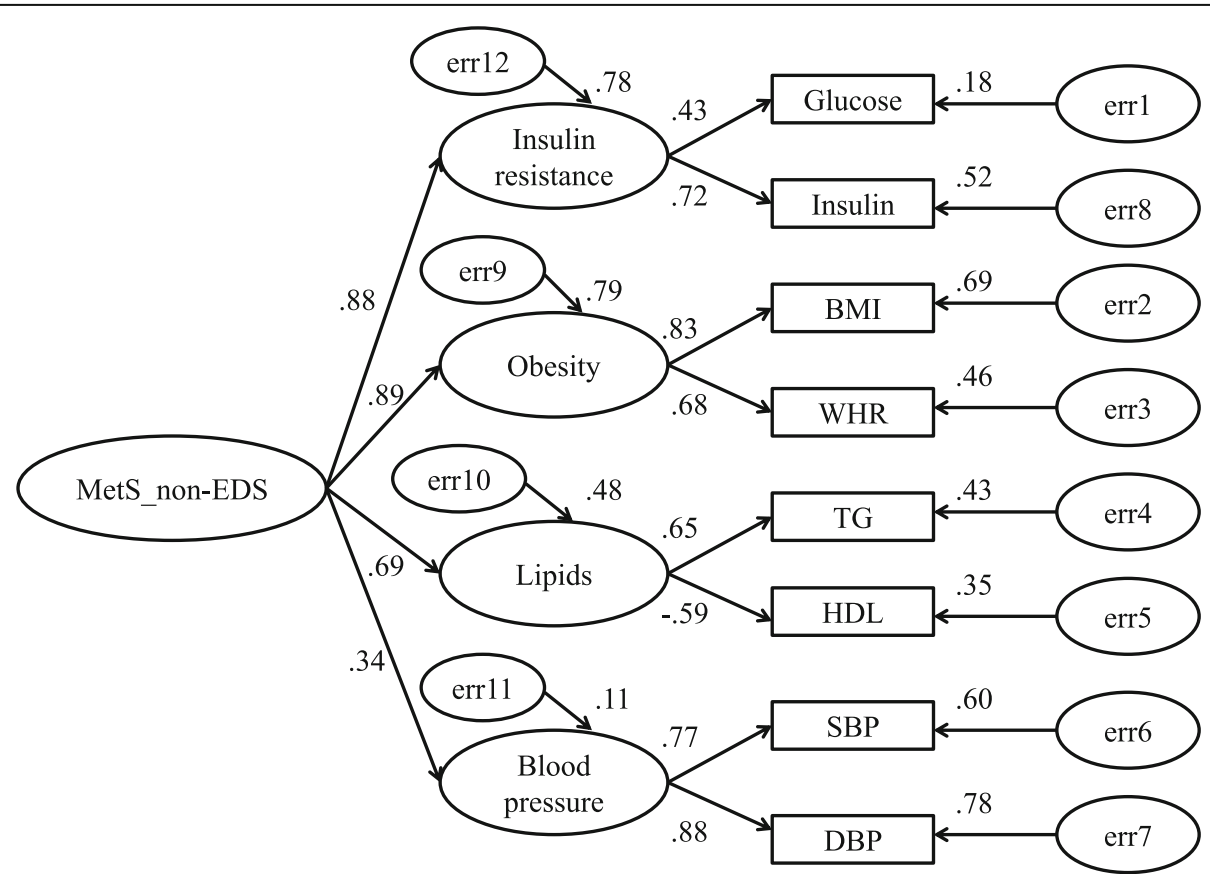

Fig. 3 Model estimation of metabolic risk factors associated with non-EDS (model 3). Correlated 4-factor model for the non-EDS. CMIN =221.854, $\mathrm{df}=23, n=2373, p<0.001, \mathrm{NC}=9.646, \mathrm{CFI}=0.969$, RMSEA $=0.060$. 'e' represents residual covariance 
Table 1 Effects of upper-airway surgery on components of MetS in patients with OSA with and without EDS

\begin{tabular}{|c|c|c|c|c|c|c|}
\hline & OSA without EDS ( $n=$ & & OSA with EDS $(n=3$ & & Differences in & p \\
\hline & $\begin{array}{l}\text { Before upper-airway } \\
\text { surgery }\end{array}$ & $\begin{array}{l}\text { After upper-airway } \\
\text { surgery }\end{array}$ & $\begin{array}{l}\text { Before upper-airway } \\
\text { surgery }\end{array}$ & $\begin{array}{l}\text { After upper-airway } \\
\text { surgery }\end{array}$ & $\begin{array}{l}\text { after-before upper- } \\
\text { airway surgery be- } \\
\text { tween patients } \\
\text { with and without } \\
\text { EDS }(95 \% \mathrm{Cl})\end{array}$ & value \\
\hline $\begin{array}{l}\text { Glucose } \\
(\mathrm{mmol} / \mathrm{L})\end{array}$ & $5.43(0.72)$ & $5.00(1.48)$ & $5.28(0.69)$ & $5.03(1.14)$ & $-0.28(-0.76 \sim 0.21)$ & 0.61 \\
\hline $\begin{array}{l}\text { Insulin }(\mu \mathrm{U} / \\
\mathrm{mL})\end{array}$ & $10.50(4.95)$ & $10.65(4.83)$ & $15.83(11.05)$ & 15.66(8.00) & $-1.81(-4.51 \sim 0.89)$ & 0.94 \\
\hline HOMA-IR & $3.39(2.59)$ & $2.79(2.14)$ & $3.93(2.56)$ & $3.33(2.86)$ & $-0.60(-1.21 \sim 0.01)$ & 0.70 \\
\hline $\mathrm{TC}(\mathrm{mmol} / \mathrm{L})$ & 4.93(0.76) & $4.83(0.84)$ & $4.96(1.02)$ & $4.57(0.76)$ & $\begin{array}{l}-0.33(-0.54 \sim- \\
0.12)\end{array}$ & 0.69 \\
\hline $\mathrm{TG}(\mathrm{mmol} / \mathrm{L})$ & $2.16(1.98)$ & $2.55(3.69)$ & $2.74(2.42)$ & $2.19(0.95)$ & $-0.03(-0.82 \sim 0.76)$ & 0.91 \\
\hline $\mathrm{HDL}(\mathrm{mmol} / \mathrm{L})$ & $1.06(0.21)$ & $1.00(0.19)$ & $1.14(0.29)$ & $1.09(0.24)$ & $-0.04(-0.09 \sim 0.01)$ & 0.70 \\
\hline LDL(mmol/L) & $3.29(0.83)$ & $2.95(0.65)$ & $3.14(0.51)$ & $2.87(0.63)$ & $\begin{array}{l}-0.31(-0.51 \sim- \\
0.11)\end{array}$ & 0.86 \\
\hline $\mathrm{SBP}(\mathrm{mmHg})$ & $126.00(13.23)$ & $128.86(14.78)$ & $128.80(15.88)$ & $123.90(14.45)$ & $-2.41(-8.75 \sim 3.93)$ & 0.34 \\
\hline $\mathrm{DBP}(\mathrm{mmHg})$ & $81.21(7.10)$ & $82.64(11.02)$ & $81.60(10.28)$ & $78.15(9.09)$ & $0.88(-5.23 \sim 7.03)$ & 0.56 \\
\hline BMI(kg/m2) & $28.26(4.93)$ & 27.68(3.82) & $28.36(2.85)$ & 27.82(3.35) & $\begin{array}{l}-0.67(-1.05 \sim- \\
0.30)\end{array}$ & 0.38 \\
\hline WHR & $0.96(0.01)$ & $0.95(0.01)$ & $0.97(0.06)$ & $0.97(0.05)$ & $-0.01(-0.03 \sim 0.01)$ & 0.67 \\
\hline
\end{tabular}

Abbreviations: $O S A$, obstructive sleep apnea; $E D S$, excessive daytime sleepiness; $B M I$, body mass index; HOMA-IR, homeostasis model of assessment for insulin resistance index; $T C$, total cholesterol; $T G$, triglycerides; $H D L-C$, high-density lipoprotein cholesterol; $L D L-C$, low-density lipoprotein cholesterol; $S B P$, systolic blood pressure; $D B P$, diastolic blood pressure

was a small but non-significant change in almost all variables. In contrast, in OSA without EDS, upper-airway surgery did not affect the variables. Thus, there was no differential effect of upper-airway surgery in OSA with and without $\operatorname{EDS}$ (all $p>0.05$ ).

\section{Discussion}

In two independent large-scale cohorts, MetS did not differ according to the presence or absence of EDS in this study. The results showed that upper-airway surgery did not modify components of MetS in OSA with and without EDS. These findings suggest that EDS may not be a useful clinical marker for MetS.

In this study, the prevalence of EDS differed between the health screening examination group and OSA group (9.2 and 33.7\%, respectively). The prevalence of EDS in the general population in our study was similar to previous reports [6] in Asian subjects. However, the prevalence of EDS was higher in our study than in previous studies, as most subjects experienced severe OSA [7]. The fact that our severe OSA patients suffered more with oxygen desaturation and fragmented sleep (micro-arousals) may explain the higher percentage of EDS in our study.

With regard to the relationship between EDS and MetS, findings have been inconsistent. In one study, EDS was significantly associated with both OSA and MetS [24]. In another investigation, daytime sleepiness in obese subjects was associated with metabolic abnormalities [8]. Also,
Bixler et al. showed that EDS was more strongly associated with metabolic factors than with OSA [25]. However, other studies have shown different results. One study found that daytime sleepiness was associated with nocturnal sleep disturbance, but not OSA and markers of MetS, in severely obese subjects [26]. However, elsewhere, EDS did not affect the relationship between OSA and metabolic variables [10]. Symptoms of EDS were not associated with sympathetic nervous system activation or arterial stiffness in non-severe OSA [27]. Furthermore, no relationship was found between EDS and stroke risk, and only weak associations were found between EDS and risk of cardiovascular and coronary heart disease [28]. MetS is an independent risk factor for pre-cardiovascular disease (CVD) and CVD; EDS may not be associated with MetS, a view consistent with our findings.

In both our EDS and non-EDS OSA subjects, obesity and insulin resistance were the main factors associated with MetS in CFA. In further analysis, EDS was independently associated with obesity. An independent relationship between EDS and obesity was also been found in previous studies $[29,30]$. One study found that EDS was associated with greater risk of central obesity, independent of diet and physical activity [29]. Another study showed that weight gain had a detrimental effect on daytime sleepiness, mostly through pathways other than OSA [30]. Weight loss interventions improve daytime sleepiness, supporting the hypothesized causal effect of obesity on daytime 
sleepiness [31]. Furthermore, we found an independent relationship between these variables even after adjusting for objective sleep parameters. The presence of EDS is associated with depressive symptoms, but not with SDB [32]. No significant difference in EDS between SDB and nonSDB subjects was found [33]. The lack of an association between EDS and OSA may explain why OSA did not affect the relationship between EDS and obesity.

\section{Limitations}

Strengths of our study included the inclusion of two large independent cohorts, and one retrospective interventional cohort, which allowed us to clearly address the relationship between EDS and MetS. Nevertheless, several limitations of the current study should be addressed. First, depression is closely associated with EDS; although we excluded subjects shown to be depressed according to selfreport measures, physician diagnosis, or anti-depression treatment status, we did not perform a clinical interview to diagnose depression. Second, we used a subjective questionnaire, the ESS, to assess EDS rather than an objective method, such as the multiple sleep latency test (MSLT). However, whether MSLT represents the gold standard to diagnose EDS remains unclear [34]. Third, visceral adipose tissue is an important factor in the development of MetS and EDS, but we measured only WHR as a marker of abdominal adiposity and not subcutaneous or abdominal fat. Fourth, certain other potential confounding factors, such as economic, nutritional and physical activity status, were not evaluated. Lastly, causation cannot be directly inferred when using a temporal cross-sectional design and selection bias may exist in retrospective cohort studies; thus, further prospective and randomized controlled studies are required to delineate the relationship between EDS and MetS.

\section{Conclusions}

The cross-sectional surveys indicated that EDS is not independently associated with MetS, but is associated with obesity in OSA. Treatment via upper-airway surgery in patients with OSA did not improve MetS, with or without EDS. The study was applied to better understand the complex relationship between excessive daytime sleepiness and metabolic syndrome in OSA.

\section{Supplementary information}

Supplementary information accompanies this paper at https://doi.org/10. 1186/s12931-019-1248-y.

Additional file 1. Description and basic characteristics of the three cohorts.

\section{Abbreviations}

BMl: Body mass index; DBP: Diastolic blood pressure." EDS: Excessive daytime sleepiness; metabolic syndrome; HC: Hip circumference; HDL-C: High-density lipoprotein cholesterol; HOMA-IR: Homeostasis model of assessment for insulin resistance index; LDL-C: Low-density lipoprotein cholesterol; MetS; NC: Neck circumference; OSA: Obstructive sleep apnea; SBP: Systolic blood pressure; TC: total cholesterol; TG: Triglycerides; WC: Waist circumference; WHR: Waist-hip ratio

\section{Acknowledgements}

The authors acknowledge the help of all doctors and nurses in Department of Otolaryngology Head and Neck Surgery \& Center of Sleep Medicine, Shanghai Jiao Tong University Affiliated Sixth People's Hospital.

\section{Authors' contributions}

Prof. HX, HY, JG and SY had full access to all of the data in the study and took responsibility for the integrity of the data and the accuracy of the data analysis. Study design: $H X, X L$ and JG; Data collection: $X L, Y Q, J Z, H X, H Y$; Statistical analysis: HH, YS; Manuscript draft: $H X, X L, H Y$; Manuscript revised: JG, SY.

All authors read and approved the final Manuscript.

\section{Funding}

This study was supported by grants-in-aid from National Key R\&D Program of China (2017YFC0112500); The Joint Project of New Frontier Technology of Shanghai Shen-kang Hospital Development Center (SHDC 12014240, 16CR3103B); Innovation Program of Shanghai Municipal Education Commission (2017-01-07-00-02-E00047); National Natural Science Foundation of China (81770987, 81700896, 81701306, 81770988); Shanghai Sailing Program (17YF1414300); multi-center clinical research project from school of medicine, Shanghai Jiao Tong University (DLY201502) and Shanghai Shen-Kang Hospital Management Center Project (SHDC12015101).

\section{Availability of data and materials}

The corresponding authors will provide the accessibility of clinical data applied to support conclusions after receiving request.

\section{Ethics approval and consent to participate}

All procedures performed in studies involving human participants were in accordance with the ethical standards of Institutional Ethics Committee of Shanghai Jiao Tong University Affiliated Sixth People's Hospital. Procedures also followed the 1964 Helsinki declaration and its later amendments. Informed consent was obtained from all individual participants included in the study.

\section{Competing interests \\ None.}

\section{Author details}

${ }^{1}$ Department of Otolaryngology Head and Neck Surgery \& Center of Sleep Medicine, Shanghai Jiao Tong University Affiliated Sixth People's Hospital, Yishan Road 600, Shanghai 200233, China. ${ }^{2}$ Shanghai Key Laboratory of Sleep Disordered Breathing, Yishan Road 600, Shanghai 200233, China.

${ }^{3}$ Otolaryngological Institute of Shanghai Jiao Tong University, Yishan Road 600, Shanghai 200233, China. ${ }^{4}$ School of Public Health, Shanghai Jiao Tong University School of Medicine, 225South Chongqing Road, Shanghai 200020, China.

Received: 18 April 2019 Accepted: 25 November 2019

Published online: 04 December 2019

References

1. Jordan AS, McSharry DG, Malhotra A. Adult obstructive sleep apnoea. Lancet. 2014;383:736-47.

2. LaGrotte C, Fernandez-Mendoza J, Calhoun SL, Liao D, Bixler EO, Vgontzas AN. The relative association of obstructive sleep apnea, obesity and excessive daytime sleepiness with incident depression: a longitudinal, population-based study. Int J Obes. 2016:40:1397-404.

3. Lindberg E, Carter N, Gislason T, Janson C. Role of snoring and daytime sleepiness in occupational accidents. Am J Respir Crit Care Med. 2001;164:2031-5.

4. Herman J, Kafoa B, Wainiqolo I, Robinson E, McCaig E, Connor J, Jackson R, Ameratunga S. Driver sleepiness and risk of motor vehicle crash injuries: a population-based case control study in Fiji (TRIP 12). Injury. 2014;45:586-91. 
5. Goncalves MA, Paiva T, Ramos E, Guilleminault C. Obstructive sleep apnea syndrome, sleepiness, and quality of life. Chest. 2004;125:2091-6.

6. Ng TP, Tan WC. Prevalence and determinants of excessive daytime sleepiness in an Asian multi-ethnic population. Sleep Med. 2005;6:523-9.

7. Kapur VK, Baldwin CM, Resnick HE, Gottlieb DJ, Nieto FJ. Sleepiness in patients with moderate to severe sleep-disordered breathing. Sleep. 2005:28:472-7.

8. Vgontzas AN, Bixler EO, Tan TL, Kantner D, Martin LF, Kales A. Obesity without sleep apnea is associated with daytime sleepiness. Arch Intern Med. 1998;158:1333-7.

9. Kritikou I, Basta M, Vgontzas AN, Pejovic S, Liao D, Tsaoussoglou M, Bixler EO, Stefanakis Z, Chrousos GP. Sleep apnoea, sleepiness, inflammation and insulin resistance in middle-aged males and females. Eur Respir J. 2014;43:145-55.

10. Bonsignore MR, Esquinas C, Barcelo A, Sanchez-de-la-Torre M, Paterno A, DuranCantolla J, Marin JM, Barbe F. Metabolic syndrome, insulin resistance and sleepiness in real-life obstructive sleep apnoea. Eur Respir J. 2012;39:1136-43.

11. Ren R, Li Y, Zhang J, Zhou J, Sun Y, Tan L, Li T, Wing YK, Tang X. Obstructive sleep apnea with objective daytime sleepiness is associated with hypertension. Hypertension. 2016;68:1264-70.

12. Hayley AC, Williams LJ, Kennedy GA, Berk M, Brennan SL, Pasco JA. Excessive daytime sleepiness and metabolic syndrome: a cross-sectional study. Metabolism. 2015:64:244-52.

13. Huang JF, Chen LD, Lin QC, Chen GP, Yu YH, Huang JC, Zhao JM. The relationship between excessive daytime sleepiness and metabolic syndrome in severe obstructive sleep apnea syndrome. Clin Respir J. 2016;10:714-21.

14. Fu Y, Xu H, Xia Y, Qian Y, Li X, Zou J, Wang Y, Meng L, Tang X, Zhu H, et al. Excessive daytime sleepiness and metabolic syndrome in men with obstructive sleep apnea: a large cross-sectional study. Oncotarget. 2017;8: 79693-702.

15. Barcelo A, Barbe F, de la Pena M, Martinez P, Soriano JB, Pierola J, Agusti AG. Insulin resistance and daytime sleepiness in patients with sleep apnoea. Thorax. 2008;63:946-50.

16. Lai CC, Lin PW, Lin HC. Effects of Upper Airway Surgery on Daytime Sleepiness in Nonobese Patients with Obstructive Sleep Apnea/Hypopnea Syndrome. 2018;127:912-8.

17. Li L, Zhan X, Wang N, Pinto JM, Ge X, Wang C, Tian J, Wei Y. Does airway surgery lower serum lipid levels in obstructive sleep apnea patients? A retrospective case review. Med Sci Monit. 2014;20:2651-7.

18. Johns MW. A new method for measuring daytime sleepiness: the Epworth sleepiness scale. Sleep. 1991;14:540-5.

19. Johns M, Hocking B. Daytime sleepiness and sleep habits of Australian workers. Sleep. 1997;20:844-9.

20. Xu H, Guan J, Yi H, Zou J, Meng L, Tang X, Zhu H, Yu D, Zhou H, Su K, et al. Elevated low-density lipoprotein cholesterol is independently associated with obstructive sleep apnea: evidence from a large-scale cross-sectional study. Sleep Breath. 2016;20:627-34.

21. Grundy SM, Cleeman JI, Daniels SR, Donato KA, Eckel RH, Franklin BA, Gordon DJ, Krauss RM, Savage PJ, Smith SC Jr, et al. Diagnosis and management of the metabolic syndrome: an American Heart Association/ National Heart, Lung, and Blood Institute scientific statement. Circulation. 2005;112:2735-52.

22. McAuley KA, Williams SM, Mann JI, Walker RJ, Lewis-Barned NJ, Temple LA, Duncan AW. Diagnosing insulin resistance in the general population. Diabetes Care. 2001;24:460-4

23. Iber CA-IS, Chesson AL, Quan S. The AASM manual for the scoring of sleep and associated events: rules, terminology and technical specifications. Westchest IL Am Acad Sleep Med. 2007;2007. https://aasm.org.

24. Agrawal S, Sharma SK, Sreenivas V, Lakshmy R, Mishra HK. Stepped approach for prediction of syndrome $Z$ in patients attending sleep clinic: a north Indian hospital-based study. Sleep Breath. 2012;16:621-7.

25. Bixler EO, Vgontzas AN, Lin HM, Calhoun SL, Vela-Bueno A, Kales A. Excessive daytime sleepiness in a general population sample: the role of sleep apnea, age, obesity, diabetes, and depression. J Clin Endocrinol Metab. 2005;90:4510-5

26. Dixon JB, Dixon ME, Anderson ML, Schachter L, O'Brien PE. Daytime sleepiness in the obese: not as simple as obstructive sleep apnea. Obesity (Silver Spring). 2007;15:2504-11.

27. Bisogni V, Pengo MF, Drakatos P, Maiolino G, Kent B, Rossitto G, Steier J, Rossi GP. Excessive daytime sleepiness does not correlate with sympathetic nervous system activation and arterial stiffening in patients with mild-to-moderate obstructive sleep apnoea: a proof-of-principle study. Int J Cardiol. 2017;236:458-61.
28. Ogilvie RP, Lakshminarayan K, Iber C, Patel SR, Lutsey PL. Joint effects of OSA and self-reported sleepiness on incident CHD and stroke. Sleep Med. 2018;44:32-7.

29. Maugeri A, Medina-Inojosa JR, Kunzova S, Agodi A, Barchitta M, Sochor O, Lopez-Jimenez F, Geda YE, Vinciguerra M. Sleep duration and excessive daytime sleepiness are associated with obesity independent of diet and physical activity. Nutrients. 2018;10:E1219. https://doi.org/10.3390/ nu10091219.

30. Ng WL, Orellana L, Shaw JE, Wong E, Peeters A. The relationship between weight change and daytime sleepiness: the sleep heart health study. Sleep Med. 2017:36:109-18.

31. Ng WL, Stevenson CE, Wong E, Tanamas S, Boelsen-Robinson T, Shaw JE, Naughton MT, Dixon J, Peeters A. Does intentional weight loss improve daytime sleepiness? A systematic review and meta-analysis. Obes Rev. 2017; 18:460-75.

32. Ohashi M, Kohno T, Kohsaka S, Fukuoka R, Hayashida K, Yuasa S, Sano M, Takatsuki S, Fukuda K. Excessive daytime sleepiness is associated with depression scores, but not with sleep-disordered breathing in patients with cardiovascular diseases. Circ J. 2018;82:2175-83.

33. Siarnik P, Klobucnikova K, Surda P, Putala M, Sutovsky S, Kollar B, Turcani P. Excessive daytime sleepiness in acute ischemic stroke: association with restless legs syndrome, diabetes mellitus, obesity, and sleep-disordered breathing. J Clin Sleep Med. 2018;14:95-100.

34. Johns MW. Sensitivity and specificity of the multiple sleep latency test (MSLT), the maintenance of wakefulness test and the Epworth sleepiness scale: failure of the MSLT as a gold standard. J Sleep Res. 2000;9:5-11.

\section{Publisher's Note}

Springer Nature remains neutral with regard to jurisdictional claims in published maps and institutional affiliations.

Ready to submit your research? Choose BMC and benefit from:

- fast, convenient online submission

- thorough peer review by experienced researchers in your field

- rapid publication on acceptance

- support for research data, including large and complex data types

- gold Open Access which fosters wider collaboration and increased citations

- maximum visibility for your research: over $100 \mathrm{M}$ website views per year

At $\mathrm{BMC}$, research is always in progress.

Learn more biomedcentral.com/submissions 